\title{
THE SINTERING MECHANISM OF ALUMINIUM AND THE ANODIZATION OF ALUMINIUM SINTERED BODIES
}

\author{
SADAO OKUMA \\ Department of Applied Science, Tokyo Denki University, Tokyo, Japan.
}

\begin{abstract}
It has been said that aluminium is hard to sinter. This is because a hard aluminium oxide film forms naturally on exposed aluminium in air, and in the case of heat-treatment for sintering, another type of hard aluminium oxide file also forms. Thus aluminium is hard to sinter at about $600^{\circ} \mathrm{C}$. The author has succeeded in manufacturing aluminium sintered bodies, by using a vacuum, an inactive gas or a reducible gas atmosphere for the sintering environment.

The possibility of producing a satisfactory dielectric on the aluminium sintered body was also investigated. An aluminium sintered body has physical properties different from aluminium foil or plate, because it is always in the porous state.

In this paper, the author presents the experimental results on aluminium sintered bodies manufactured under various conditions and the results of anodization of the sintered bodies.
\end{abstract}

\section{INTRODUCTION}

The compacted body was manufactured by pressing a mixture of the various size grades of aluminium powder together with the binder. The compacted body was sintered at $600^{\circ} \mathrm{C}$ in a vacuum atmosphere. The physical properties concerning this aluminium sintered body, that is, the density, porosity, and the intercommunicating porosity were measured. However, for convenience, the sintering mechanism was examined by using aluminium wire.

Subsequently, dielectric was grown on the aluminium sintered body by anodization in ammonium borate solution. and the electrical characteristics were determined.

\section{THEORY}

\section{$2.1 \quad$ Sintering}

For the sintering of metals, there exists four mechanisms, that is, the viscous flow, internal diffusion, surface diffusion and the vapourisation adhesion mechanisms. The second of these is the most important (see Nichols) ${ }^{1}$ and the fusion mechanism is as follows:

$$
\frac{x^{5}}{a^{2}}=\frac{10 \gamma V}{R T} \cdot D_{v} \cdot t
$$

where

$$
\begin{aligned}
& x \ldots \ldots \text { radius of contacting } \\
& \text { face }(\mathrm{cm}) \\
& a \ldots \ldots \text { radius } \quad(\mathrm{cm}) \\
& \gamma \ldots \ldots \ldots \text { surface tension } \quad\left(\text { dyne.cm }{ }^{-1}\right. \text { ) } \\
& V \ldots \ldots \ldots \text { volume of } 1 \text { mole } \quad\left(\mathrm{cm}^{3}\right) \\
& D_{\nu} \ldots \ldots \ldots \text { internal diffusion } \\
& \text { coefficient } \quad\left(\mathrm{cm}^{2} \cdot \mathrm{sec}^{-1}\right) \\
& R \ldots \ldots \text {. gas constant (dyne.cm. } \mathrm{K}^{-1} \text { ) } \\
& T \ldots \ldots \text {. . absolute temperature }(\mathrm{K}) \\
& t \ldots \ldots \text {. time } \quad \text { (sec) }
\end{aligned}
$$

This formula was derived using the following method. The work performed by contacting two sphere with radius $r_{1}$ and $r_{2}$ is shown by means of Kelvin's formula to be as follows:

$$
R T \ln \frac{P_{1}}{P_{2}}=2 V\left(\frac{1}{r_{1}}-\frac{1}{r_{2}}\right)
$$

where

$$
\begin{aligned}
& P_{1} \ldots \ldots \ldots \text { vapour pressure around the } \\
& \text { sphere } r_{1} \text { (Torr) } \\
& P_{2} \ldots \ldots \ldots \text { vapour pressure around the } \\
& \text { sphere } r_{2} \text { (Torr) }
\end{aligned}
$$

Now:

$$
\ln \frac{P_{1}}{P_{2}}=\ln \left(\frac{P_{2}+\Delta P}{P_{2}}\right)=\ln \left(1+\frac{\Delta P}{P_{2}}\right)
$$


In the case of $\Delta P / P_{2} \ll 1$, the formula is as follows:

$$
\ln \frac{P_{1}}{P_{2}}=\frac{\Delta P}{P_{2}}
$$

And in the case of $r_{1} \ll r_{2}$, the result will be as follows:

$$
\frac{\Delta P}{P_{2}}=\frac{2 V \gamma}{R T} \cdot \frac{1}{r_{1}}
$$

When $V$ become infinite, $P_{2}$ is approaches $P_{0}$ and $r_{1}=r$; therefore

$$
\Delta P=\frac{2 V \gamma}{R T \gamma} \cdot P_{0}
$$

Therefore, the smaller the radius $r$ is, the higher the pressure. The curvature radius of the sphere with radius $r$ is $2 / r$, (Figure 1).

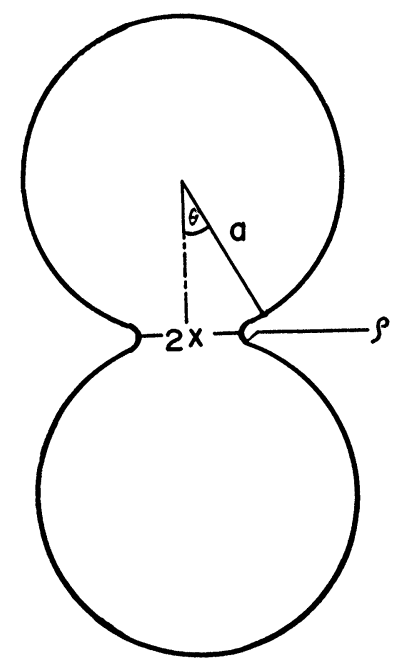

FIGURE 1 Schematic figure for relationship between $a, x$ and $\rho$.

$$
\Delta P=\frac{V \gamma P_{0}}{R T \rho}
$$

If the curvature of a convex surface is assumed to be positive, $\Delta P$ becomes negative, since the curvature of a concave surface is $-1 / \rho$. Therefore, the pressure over a concave surface $P^{\prime}$ becomes $P^{\prime}=P-\Delta P$, and is lower than the surrounding pressure. Because the area of low vapour pressure can be assumed to be lower in concentration of vapour molecules, the surface where $\Delta P<0$ conversely has a high vacancy concentration (Figure 2).
P。

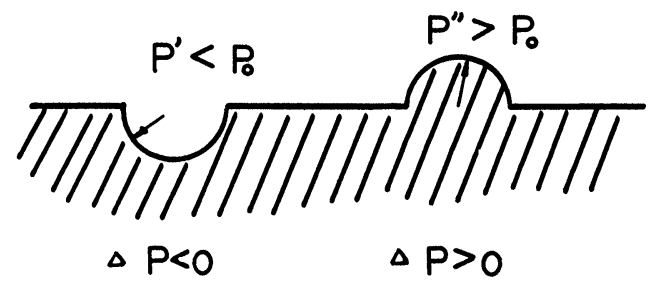

FIGURE 2 Vapour pressure over surface.

If the vacancy concentration is $C$, with concentration $C_{0}$, corresponding to pressure $P_{0}$ then:

$$
\Delta C=\frac{V \gamma}{R T \rho} \cdot C_{0} .
$$

According to Fick's diffusion formula, the excess vacancies diffuse toward the direction of dilute concentration, that is, toward the direction of the inside of the sphere. As a result, the concave part grows. Fick's first law is expressed as follows

$$
I=-D \frac{\partial c}{\partial x}=-D \operatorname{grad} C
$$

where:-

$$
\begin{aligned}
& I \ldots \ldots \ldots \text { number of vacancies } \\
& \text { flowing per } \mathrm{cm} \text { per } \\
& \mathrm{sec} \quad\left(\mathrm{cm}^{-2} \mathrm{sec}^{-1}\right) \\
& D \ldots \ldots \ldots \text { diffusion coefficient }\left(\mathrm{cm}^{2} . \mathrm{sec}^{-1}\right) \\
& C \ldots \ldots \text {..... vacancy-concentration } \\
& \text { per unit cube } \quad\left(\mathrm{cm}^{-3}\right) \\
& x \ldots \ldots \text { distance } \quad(\mathrm{cm})
\end{aligned}
$$

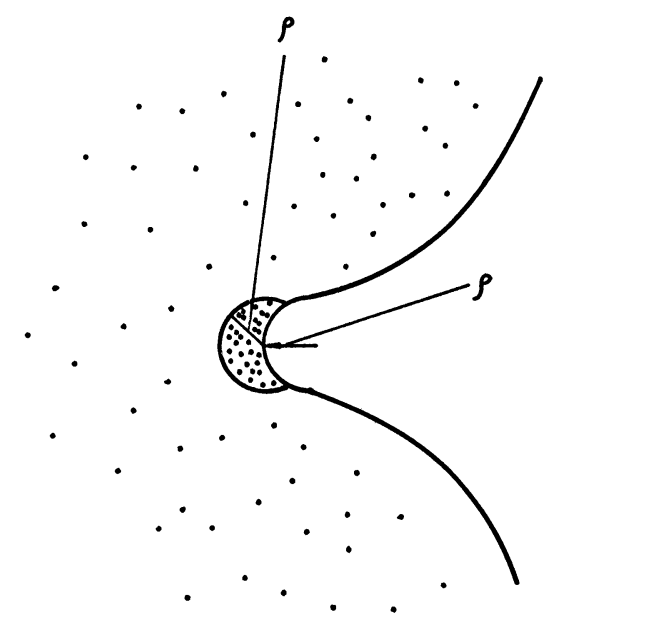

FIGURE 3 Distribution of vacancies. 
The negative sign indicates that the direction of flow of material impurities is from high to low concentration. The concentration gradient of vacancies may be of the same order as $\rho$ and thus the depth at the concave part, and at the other parts vacancies approach zero (Figure 3). Therefore, Fick's law is valid only at the concave surface where $\Delta X$ is considered to approach $\rho$. As with the concentration gradient, the distribution condition which is not zero also exists, and the formulae need to be amended. Therefore the following equation may be proposed:

$$
\frac{\Delta C}{\rho}=\frac{\partial C}{\partial x} \cdot d v
$$

where $\Delta C \ldots$ small concentration

$$
\text { of vacancies (non-dimensional) }
$$$$
\rho \ldots \text { curvature radius }(\mathrm{cm})
$$

Also, according to the definition of Fick's law, the number of vacancies is unity for diffusion during unit time across a unit area cross-section. Consequently, the following equation is obtained:

$$
I=\frac{1}{d t} \cdot \frac{1}{A}
$$

$$
\begin{aligned}
\text { where } t \ldots \text { time } & (\mathrm{sec}) \\
A \ldots \text { area } & \left(\mathrm{cm}^{2}\right)
\end{aligned}
$$

Substituting Eq's. (7) and (8) in Eq. (6) we obtain:

$$
\frac{1}{d t} \cdot \frac{1}{A}=D_{\nu}^{\prime} \cdot \frac{1}{d V} \cdot \frac{\Delta C}{\rho}
$$

where $D_{\nu}^{\prime}$ is the internal diffusion coefficient for vacancies $\left(\mathrm{cm}^{2} \cdot \mathrm{sec}^{-1}\right)$ which can be rewritten as follows:

$$
A \cdot \frac{\Delta C}{\rho} \cdot D_{\nu}^{\prime}=\frac{d V}{d t}
$$

In Figure 4, $A$ and $V$ are area and volume respectively. Thus

$$
\rho=\frac{x^{2}}{2 a}
$$

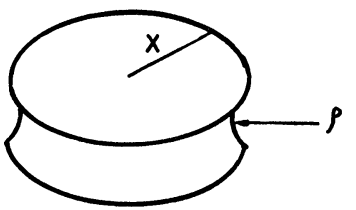

FIGURE 4 Schematic figure for relationship between $x$ and $\rho$. where $a$ is the radius of the sphere (see Figure 1) and

$$
A=2 \pi x \cdot 2 \rho \text {. }
$$

Therefore

$$
A=\frac{2 \pi x^{3}}{a} \quad \text { and } \quad V=\pi x^{2} \cdot 2 \rho=\pi x^{4} / a
$$

Substituting the above relation and using Eq. (5),

$$
\begin{gathered}
\frac{d v}{d t}=\frac{d v}{d x} \cdot \frac{d x}{d t}=\frac{4 \pi x^{3}}{a} \cdot \frac{d x}{d t} \\
\frac{2 \pi x^{3}}{a} \cdot \frac{\gamma V}{R T x^{4} / 4 a^{3}} \cdot D_{\nu}^{\prime} \cdot C_{0}=\frac{4 \pi x^{3}}{a} \cdot \frac{d x}{d t}
\end{gathered}
$$

On the other hand, the following relation exists:-

$$
D_{\nu}=D_{\nu}^{\prime} \exp \left(-\frac{Q}{R T}\right)
$$

where $Q \ldots$ activation energy (cal)

(i.e. $Q$ is the energy to form 1 mole vacancy point).

Therefore, the exponential term $(-Q / R T)$ equals to $C_{0}$, the equilibrium concentration of vacancy points in 1 mole. Eq. (12) can be written as:

$$
D_{\nu}=D_{\nu}^{\prime} \cdot C_{0}
$$

When Eq. (12') is substituted for Eq. (11), Eq. (1) becomes:

$$
\frac{x^{5}}{a^{2}}=\frac{10 \gamma V}{R T} \cdot D_{\nu} \cdot t
$$

or

$$
5 \ln x=\left(\frac{10 a^{2} \gamma V}{R T} \cdot D_{\nu}\right)+\ln t
$$

\subsection{Anodization}

Aluminium is usually anodized to form an oxide on the surface. A porous aluminium oxide file is formed during anodization using an electrolyte with a solvent action. The film obtained consists of an amorphous $\mathrm{Al}_{2} \mathrm{O}_{3}$. On the contrary, when electrolyte with no solvent action is used as the forming solution, the aluminium oxide film is non-porous and of $\gamma$ or $\gamma^{\prime}$ crystalline $\mathrm{Al}_{2} \mathrm{O}_{3} .{ }^{2}$ The structure of $\gamma$ or $\gamma^{\prime}$ crystalline $\mathrm{Al}_{2} \mathrm{O}_{3}$ is found, by means of the electron beam diffraction using the permeation method ${ }^{3}$ to have a lattice constant of 7,9 $\AA$. The oxide $\gamma-\mathrm{Al}_{2} \mathrm{O}_{3}$ itself is not recognized as having a defined lattice constant, but it is considered to be in an amorphous state. ${ }^{4}$ 


\section{EXPERIMENTAL}

\subsection{Sintering}

The sintering temperature was measured at a pressure of $10^{-4}$ to $10^{-5}$ Torr by detecting when aluminium wire of $0.5 \mathrm{~mm}$ diameter commenced sintering with an aluminium plate. Measurement of the sintering mechanism was carried out at a pressure of $10^{-4}$ to $10^{-5}$ Torr, using 3 to 5 pieces of twisted aluminium wire of $0.5 \mathrm{~mm}$ in diameter.

The radius was measured by assuming a sphere, and the radius $x$ of the contacting face which was formed by sintering was measured by a photographic technique.

\subsection{Manufacturing of Aluminium Sintered Body}

A $99.98 \%$ to $99.99 \%$ pure aluminium powder was obtained from commericial sources. Particle sizes of the aluminium powder were of 70,100,150 and 200 mesh. Two kinds of aluminium powder were employed for sintering, coarse powder and fine powder. The fine powder consisted of 200 mesh, and the coarse powder was a mixture of $30 \mathrm{Wt} \%$ of 70 , and of 100 , and of 150 mesh and $10 \mathrm{Wt} \%$ of 200 mesh.

To compact the coarse and fine aluminium powders, the required pressure was between
$250 \mathrm{~kg} / \mathrm{cm}^{2}$ and $1700 \mathrm{~kg} / \mathrm{cm}^{2}$. The size of the compacted particle was $5 \mathrm{~mm}$ in diameter and about $5 \mathrm{~mm}$ high. The sintering was carried out at $600^{\circ} \mathrm{C}$ for $120 \mathrm{~min}$ at a pressure of $10^{-4}$ to $10^{-5}$ Torr.

\subsection{Manufacturing of Aluminium Oxide as Dielectric}

The forming solution was $3 \%$ ammonium penta borate solution $\left(\mathrm{NH}_{4} \mathrm{~B}_{5} \mathrm{O}_{8}\right)$. The anodization was performed at a constant voltage of $30 \mathrm{~V}$ for the fine powder and $50 \mathrm{~V}$ for the coarse powder, taking 3 hours in both cases.

After formation, the elements $(5 \mathrm{~mm}$ diameter and about $5 \mathrm{~mm}$ high) were sliced into specimens of $1 \mathrm{~mm}$ wide and $1 \mathrm{~mm}$ high by a diamond cutter to examine the distribution of aluminium oxide as dielectric. The sliced specimens were observed by a scanning electron microscope Y-7, manufactured by Japan Electron Optics Laboratory (JEOL).

\subsection{Measurement of the Electrical Characteristics}

The electrolyte for measurement of the electrical characteristics was a saturated solution of ammonium penta borate $\left(\mathrm{NH}_{4} \mathrm{~B}_{5} \mathrm{O}_{8}\right)$. The electrical characteristics were measured using a Universal Bridge manufactured by Yokogawa Electrical Manufacturing Company, Tokyo.

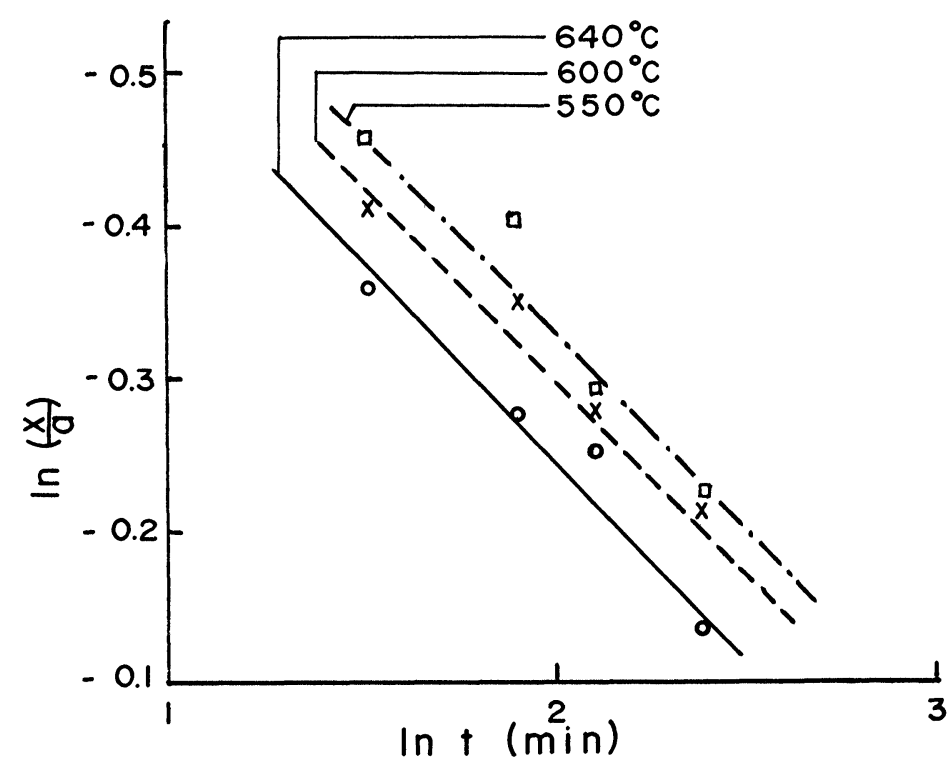

FIGURE 5 Relationship between $x$ and $t$ at various temperatures. 


\subsection{Sintering Temperature}

The temperature was $500^{\circ} \mathrm{C}$ and the pressure $10^{-4}$ to $10^{-5}$ Torr when the aluminium wire of $5 \mathrm{~mm}$ diameter started sintering with the aluminium plate.

\subsection{Sintering Mechanism}

From Eq. (13) it can be seen that $\ln x / a$ vs. $\ln t$ should give a straight line. Experimental values showed that this was the case and that the power of $X$ in Eq. (1) was between 5.1 and 4.8. The result is shown in Figure 5. Figures 6 and 7 show SEM pictures of broken and sliced sintered bodies.

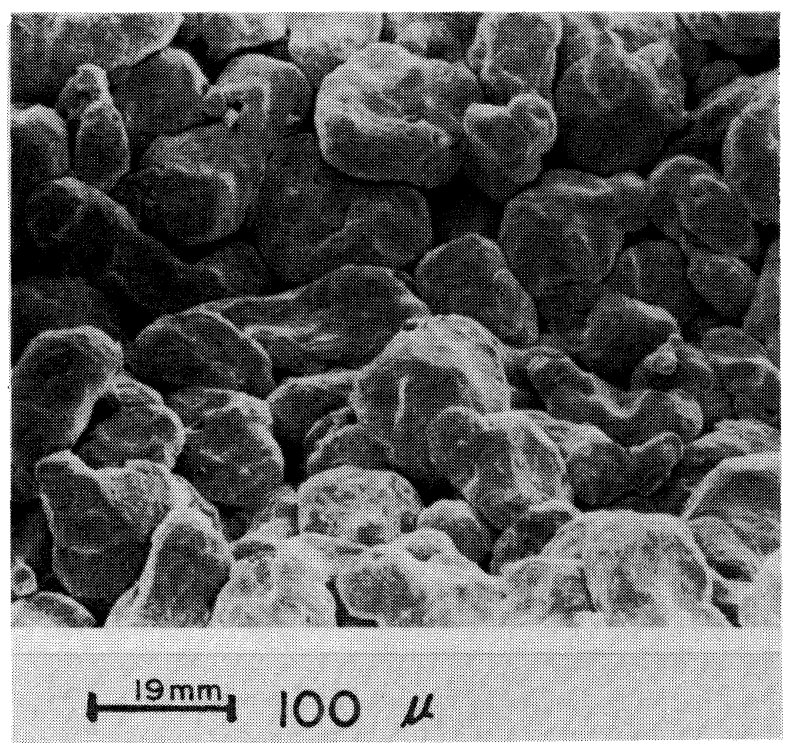

FIGURE 6 Scanning electron micrograph of broken specimen.

\subsection{Aluminium Oxide as Dielectric}

The purpose of the electron beam diffraction studies was to analyse the distribution of the aluminium oxide as dielectric. Unfortunately the sliced specimens showed only the electron beam diffraction image of aluminium.

\subsection{Electrical Characteristics}

The relation between the electrical characteristics and the compacting pressure at $120 \mathrm{~Hz}$ of frequency is shown in Figure 8, for the sintered and anodised products using both coarse and fine powders.

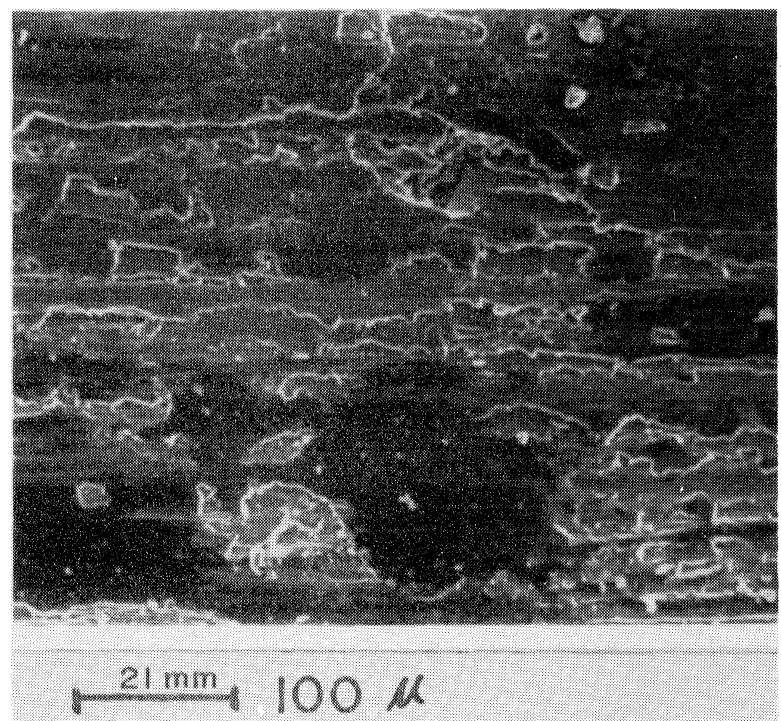

FIGURE 7 Scanning electron micrograph of sliced specimen.

\section{DISCUSSION AND CONCLUSION}

\subsection{Sintering Mechanism}

From the results shown in Figure 5, it was found that if the power $n$ of $x$ in Eq. (1) is between 5.1 and $4.8, x^{n}$ is linearly proportional to time. This relation agrees with Eq. (1). Thus the sintering mechanism of aluminium is considered to be due to the internal diffusion as assumed by Kuczynski ${ }^{5}$. From the experimental results, $\ln 10 a^{2} \gamma V / R T \cdot D_{\nu}$ is obtained from the intersection in Figure 5. From this value, $D_{\nu}$ can be calculated. If $\ln D$ is plotted against $1 / T$, using Eq. (12), $D_{\nu}$ and $Q$ can be determined to have values $1 \mathrm{~cm}^{2} \mathrm{sec}^{-1}$ and $20 \mathrm{kcal} . \mathrm{mol}^{-1}$, respectively. The value of $20 \mathrm{kcal}^{\mathrm{mol}} \mathrm{m}^{-1}$ is considered to be a reasonable value for the metal.

\subsection{Aluminium Oxide as Dielectric}

One of the purposes of this paper is to examine the distribution of $\gamma-\mathrm{Al}_{2} \mathrm{O}_{3}$. The reason that the sliced specimens have shown only the electron beam diffraction image of aluminium, is that the specimens were too soft for the diamond cutter and this covered on the surface with aluminium powder. This can be seen in the electron microscope photographs of the surface in Figures 6 and 7. Figure 6 is a photograph of a specimen broken open. (The specimens were broken open at about one half of the height.) 


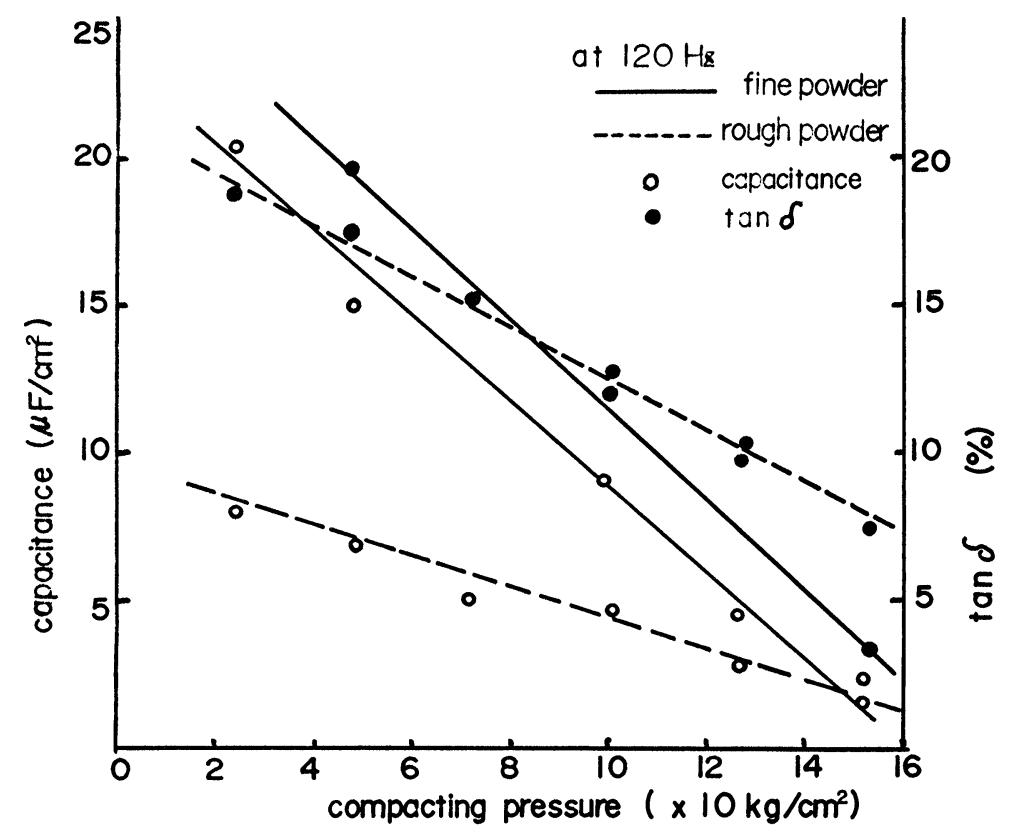

FIGURE 8 Relation between compacting pressure and electrical characteristics.

Although the particles can be observed distinctly in Figure 6, the particles cannot be seen in Figure 7.

From these observations, it can be assumed that the sliced specimens were covered with aluminium powder. Therefore, results of electron beam diffraction examination would only show an aluminium pattern. However $\gamma-\mathrm{Al}_{2} \mathrm{O}_{3}$ (with $7.9 \AA$ lattice constant) as dielectric has already been reported using electron beam diffraction techniques. For such a measurement a sample of aluminium oxide was used which had been removed from the aluminium substrate by chemical treatment. For electron beam diffraction analysis, the sample needed to be of the order of $1 \AA$ thick.

\subsection{Electrical Characteristics}

The aluminium sintered body is porous. Therefore, the aluminium sintered body is difficult to compare with aluminium foil or plate. The density of the aluminium sintered body was 1.2 to $1.9 \mathrm{~g} / \mathrm{cm}^{3}$ under a compacting pressure of 250 to $1700 \mathrm{~kg} / \mathrm{cm}^{2}$. This compares with the density of $2.7 \mathrm{~g} / \mathrm{cm}^{3}$ for aluminium metal.

As mentioned above, the surface area can be increased by the sintering process. Table I shows a comparison of the electrical characteristics for various aluminium electrolytic capacitors.
As clearly seen from Figure 8 and Table I, the sintered-type aluminium electrolytic capacitor manufactured in this study is considered to have a good performance. Concerning the fine and the coarse aluminium powders, it was observed that the smaller the compacting pressure, the larger the electrical capacitance.

Generally in the case of aluminium electrolytic capacitors, the wire foil and plate of aluminium are usually etched to make the surface area greater. ${ }^{6}$ By this etching, the surface area is increased between 5 to 20 times compared with the original surface. Aluminium oxide dielectric capacitors manufactured by forming plane aluminium at $30 \mathrm{~V}$, theoretically show an electrical capacitance of $0.16 \mu \mathrm{F} / \mathrm{cm}^{2}$. Etched aluminium electrolytic capacitors show an electrical capacitance from about $0.8 \mu \mathrm{F} / \mathrm{cm}^{2}$ to about $3.2 \mu \mathrm{F} / \mathrm{cm}^{2}$.

The electrical capacitance of the sintered-type aluminium electrolytic capacitors manufactured in this study were as large as 7 to $13 \mu \mathrm{F} / \mathrm{cm}^{2}$ as shown in Figure 8 and Table I.

Tantalum electrolytic capacitors are also made by sintering and it is useful to compare surface gains between the two systems. In the case of tantalum, figures are quoted in terms of $\mu \mathrm{F} / \mathrm{mm}^{3}$, for a $10 \mathrm{~V}$ anodization, and for a liquid electrolyte structure, this can be of the order of $10^{-1}$. In the case of 
TABLE 1 Comparison of aluminium electroly te capacitors

\begin{tabular}{|c|c|c|c|c|c|c|c|}
\hline & Form & Etching & $\begin{array}{l}\text { Gaseous } \\
\text { atmosphere } \\
\text { to sintering }\end{array}$ & $\begin{array}{l}\text { Forming } \\
\text { solution }\end{array}$ & $\begin{array}{l}\text { Forming } \\
\text { voltage }(V)\end{array}$ & $\begin{array}{l}\text { Capacitance } \\
\text { per area } \\
\left(\mu \mathrm{F} / \mathrm{cm}^{2}\right)\end{array}$ & $\begin{array}{l}\text { Dissipation } \\
\text { factor }(\%)\end{array}$ \\
\hline $\begin{array}{l}\text { Aluminium } \\
\text { solid } \\
\text { electrolytic } \\
\text { capacitor }\end{array}$ & Foil & Done & $\longrightarrow$ & $\begin{array}{l}\text { Ammonium } \\
\text { borate } \\
\left(\mathrm{NH}_{4} \mathrm{~B}_{5} \mathrm{O}_{8}\right)\end{array}$ & $\begin{array}{c}6 \\
\dot{10} \\
\dot{25}\end{array}$ & $\begin{array}{c}5 \\
\dot{2.7} \\
0.6\end{array}$ & $\begin{array}{l}10 \\
\cdot \\
8 \\
\cdot \\
6\end{array}$ \\
\hline $\begin{array}{l}\text { Sintered-type } \\
\text { aluminium } \\
\text { electrolytic } \\
\text { capacitor } \\
\text { in this study }\end{array}$ & Sintered-type & None & Vacuum & , & $\begin{array}{c}30 \\
\dot{50}\end{array}$ & $\int_{7}^{13}$ & $\int_{5}^{10}$ \\
\hline
\end{tabular}

sintered aluminium structure this figure can be $3 \times 10^{-2}$.

Thus the surface area of the aluminium sintered body was found to be several times as large as the etched aluminium. Therefore, the purpose of this study which was to increase the electrical capacitance by increasing the surface area using sintered aluminium powder has been achieved. Likewise, the dissipation factor of the sintered-type aluminium electrolytic capacitor in this study is not too large in comparison with the aluminium solid electrolytic capacitor (Figure 8 and Table I).

If the dissipation factor is required to be smaller, it may be attainable by a surface pretreatment before anodization. Therefore, from these results, it is concluded that the sintered-type aluminium electrolytic capacitor in this study is considered to be of practical value ${ }^{8-12}$.

\section{ACKNOWLEDGEMENTS}

The author is extremely grateful to Prof. Sakae Tajima,
Tokyo City University, for his valuable suggestions and to Mr. Hozui Ohkubo, Tokyo Denki University for his co-operation for submission of this paper.

\section{REFERENCES}

1. F. A. Nichols. J. Appl. Phys. 37, p. 2805 (1966).

2. C. J. Dell'Oca, D. L. Pulfrey and L. Young "Anodic Oxide Films" Physics of Thin Films, 6, p. 1 (1977).

3. N. F. Mott: Trans. Faraday Soc. 43, p. 429 (1947).

4. D. J. Stirland; R. W. Bicknall. J. Electrochem. Soc. 106, p. 481 (1959).

5. C. C. Kuzynski: Trans. Am. Inst: Mining Met. Engrs. 185, p. 169 (1949).

6. A. L. Jenny, R. A. Ruscetta. J. Electrochem. Soc. 108, p. 442 (1961).

7. D. S. Campbell. Rad and Elec Eng. 41, p. 5 (1971).

8. S. Okuma and T. Nemoto: J. Metal Finishing Soc. Japan, 23, p. 204 (1972).

9. S. Okuma and T. Nemoto: ibid, 24, p. 376 (1973).

10. S. Okuma: ibid, 24, p. 626 (1973).

11. S. Okuma, T. Nemoto and H. Sakamoto; J. Electrical Engineers. Japan, 93-A, p. 501 (1973).

12. S. Okuma: J. Electrochem. Soc. (USA), 122, p. 1413 (1975). 

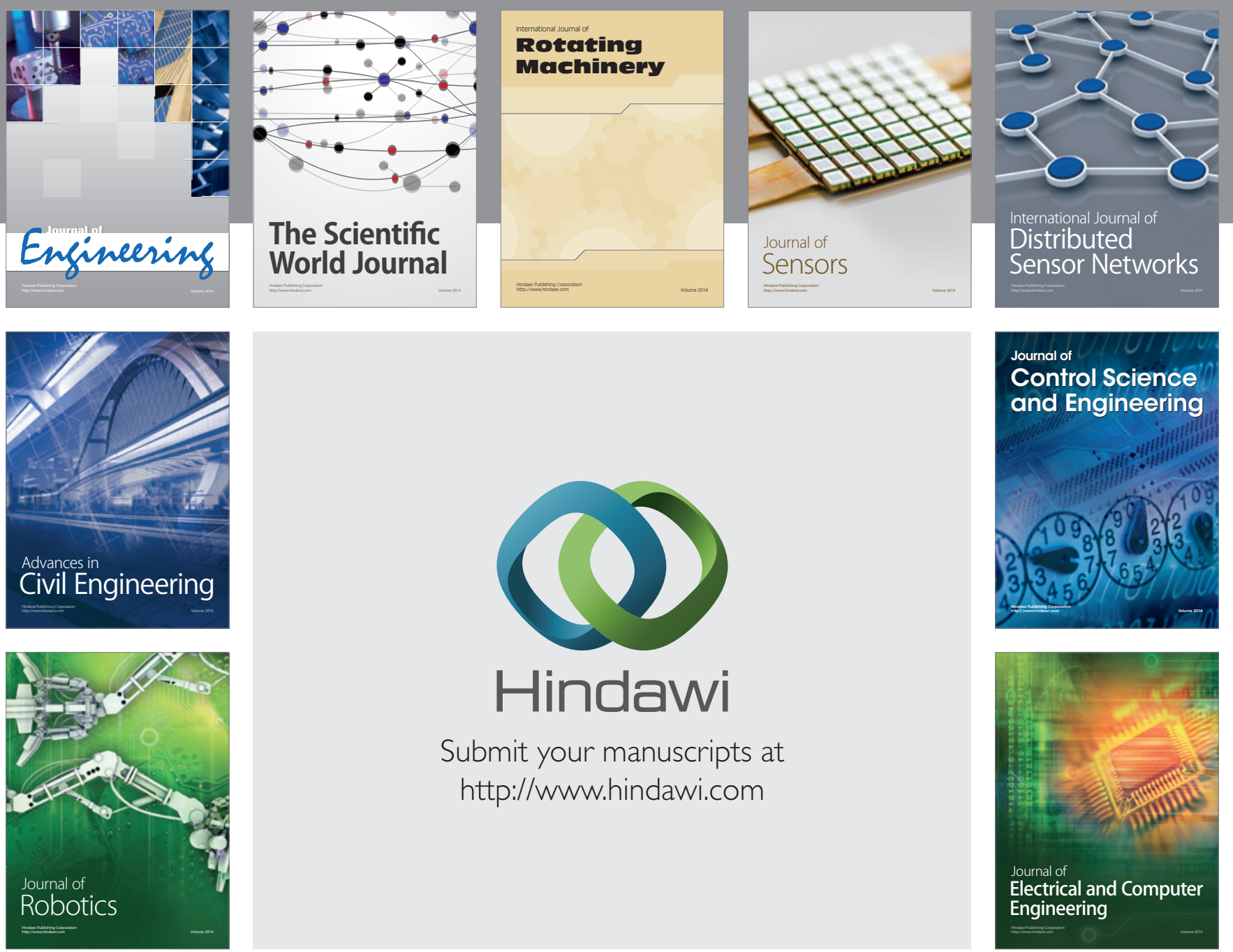

Submit your manuscripts at

http://www.hindawi.com
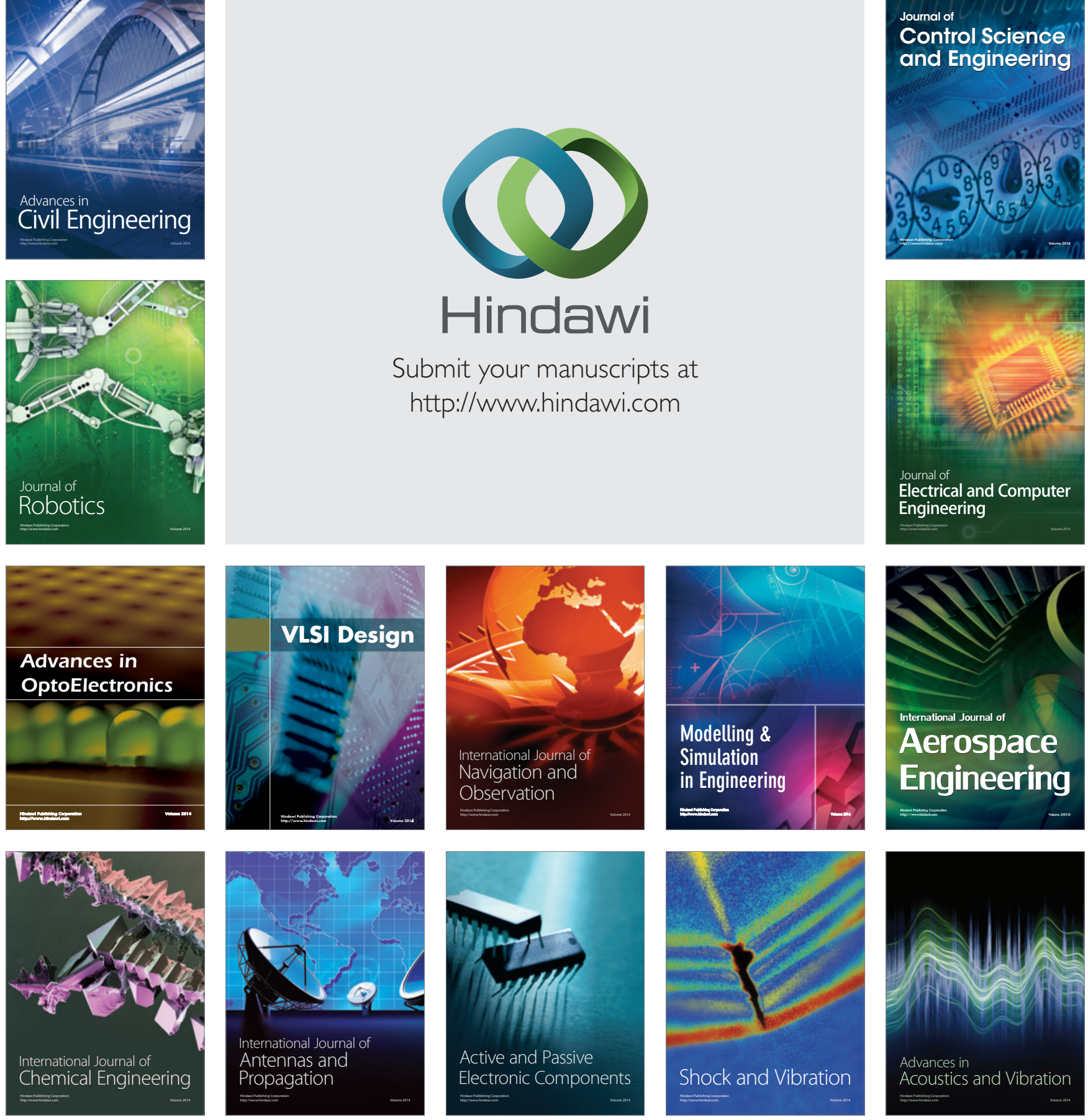